\title{
Adverse Effect of Alcoholism in A Family
}

\author{
${ }^{1}$ Oseni TIA, ${ }^{1}$ Odewale MA \\ ${ }^{I}$ Department of Family Medicine, Irrua Specialist Teaching Hospital, Irrua, Edo State, Nigeria.
}

\begin{abstract}
:
Introduction: Alcoholism aswell assubstance abuse isamajor problem globally leading to adverse effect on family life. It is asignificantcause of morbidity and mortality.

CaseReport: Presented was Mr BN,a49 year old commercialdriver who wasinvolvedin an autocrash on account of drunk driving sustaining splenic and intestinal rupture. He battered hiswife and his 7 year old daughter was hospitalised on account of burns sustained from him. His mother was depressed on account of his alcoholism and irresponsible behaviour.

Conclusion: Alcoholism has adverse effect on family life, measures therefore should be put in place to discourage drinking and alcoholics should be encouraged and helped to quit drinking.

Keywords: Alcoholism, irresponsible, behaviour, family

\section{Introduction}

Alcoholism is a major social and health problem worldwide ${ }^{1,2,3}$ accounting for $4.5 \%$ of the global burden of disease, measured by disability-adjusted life years(DALY). ${ }^{3}$ Alcohol consumption in Nigeria is among the highest globally. ${ }^{3}$ It is a major cause of disfunctionality in the family leading to increase in the rate of domestic violence particularly intimate partner violence which cuts across age, race, religion and socioeconomic boundaries, ${ }^{4}$ with women commonly being the victims and men the perpetrators ${ }^{4,5}$ especially in patriarchal societies like Nigeria. ${ }^{5}$ The children also suffer neglect as a result of alcoholism.
\end{abstract}

\section{Case Report}

He was Mr BN, a 49 year old commercial driver who resided in Auchi, Edo State, Nigeria. He was driving his father's car after taking three bottles of beer when he veered off the road and crashed into a tree.He was not wearing his seat belt. He sustained facial laceration, splenic rupture as well as intestinal rupture. He had exploratory laparotomy and bowel resection and anastomosis as well as splenectomy.He had earlier beaten his wife in the kitchen where he mistakenly pushed the cooking stove and its contents fell on his 7 year old daughter who was also hospitalised for two weeks for second degree superficial partial thickness burns. He had dropped the daughter and her mother at the hospital before returning to drink. The accident happened as he was returning from where he went to drink. He has been involved thrice in a road traffic accident all under the influence of alcohol, killing a bystander in one of them. He did not sustain major injuries in the previous accidents.

He drank up to three bottles of beer a day and occasionally took illicit gin (kain-kain) in addition to smoking cigarette (smoked 20 pack years). He drank even when he could not afford other things. He met all the CAGE criteria for alcoholism (Feeling the need to cut down on drinking; getting annoyed when his drinking habit is criticised; feeling guilty about drinking and needing to drink first thing in the morning as an eye opener). He was having frequent financial difficulties leading to much indebtedness which the father had to pay from time to time. He lived in a three room apartment in his father's house with his wife and children. His mother was also being managed for depression and hypertension on account of his substance abuse and irresponsibility to his family.

He was discharged after two weeks on admission. Prior to discharge, a family conference was held with the family physician, the surgeon, the patient, his wife, his father and his motherall present. He was counselled on the need to quit which he pledged to do and his family promised to help him quit alcoholism and substance abuse.

\section{Discussion}

Alcoholism is a major problem worldwide. ${ }^{1}$ Its consumption in Nigeria is one of the highest globally. ${ }^{3}$ It is a major cause of road traffic accident in Nigeria accounting for over $50 \%$ of accident cases and with over two third of commercial drivers drinking with a history of bingeing in three quarter of them. ${ }^{6} \mathrm{Mr} \mathrm{BN}$, a commercial driver has been involved in a number of road traffic accidents as a result of drunk driving even killing a bystander in one of them. Such practices should not be allowed to thrive in our society. Measures, including appropriate legislation and their enforcement, should be put in place to limit sale and consumption of alcohol particularly to commercial drivers to minimise/forestall mishaps on our roads.Peer influence could 
probably have encouraged his drinking habit as alcoholism has been found to be high among commercial drivers, Mr BN's profession and peer influence has been identified as a risk factor for substance (including alcohol) abuse. ${ }^{7}$

Patient's alcoholism has significantly had adverse effects on his family. Apart from the wife who was constantly subjected to physical, social, psychological and emotional abuse from the husband, the children also suffered neglect. His daughter sustained partial thickness burns as a fallout of a fight between him and his wife. This led to her hospitalisation for two weeks. She was however treated with no adverse sequelae.

Most cases of burns commonly encountered are as a result of domestic accidents. ${ }^{8}$ Adopting safety measures at home such as keeping away fuel in safe places and avoiding fight particularly in places like kitchen when cooking would help reduce the scourge.

Anotherfallout of the patient's alcoholism was depression in his mother. Depression is very common in our environment and globally, ${ }^{9,10}$ with most of the patients (over 90\%) seen in family practice clinics. ${ }^{9}$ The fact that most depressed patients present with somatoform disorders make the condition often underdiagnosed or over treated. ${ }^{9}$ As family physicians who are saddled with the provision of primary care for which mental health has been integrated in Nigeria, we should equip ourselves with the required proficiency in the diagnosis and management of depression.

Alcohol use disorder in inpatients was found to be high in a Nigerian study. ${ }^{2,7}$ This means hospitalisation, even when it is for other conditions, should be used as an opportunity to identify people with alcohol use disorders and help them correct it. Though Mr BN came to the hospital on account of injuries sustained in a road traffic accident, this provided us the opportunity of identifying his main problem alcoholism, which led to the accident in the first place, and have been a serious cause of problems in the family. The intervention of the health team leading to his subsequent quitting of drinking had helped restore peace in his home as evident from his wife's claim during follow up that he beat her less and was more responsible. Similar cases abound in the society, therefore we should use the opportunity of contact with patients to explore their other problems particularly psychosocial problems as this and address them for a more functional family life.

\section{References}

[1]. Oduola T, Adeosun OG, Oduola TA, Agbaje NR, Raheem ZA. Drinking patterns: biochemical and haematological findings in alcohol consumers in Ile-Ife, Nigeria. Afr. J. Biotechnol. 2005;4(11):1304-1308

[2]. Okonoda KM, Audu MD, Obindo TJ, James BO. Prevalence of alcohol use disorders among medical and surgical in-patients at a Teaching Hospital in North Central Nigeria. Jos Journal of Medicine. 2014;8(2):22-28

[3]. Chukwuonye II, Chuku A, Onyeonoro UU, Madukwe OO, Oviasu E, Ogah OS. A rural and urban cross-sectional study on alcohol consumption among adult Nigerians in Abia state. Int J Med Biomed Res 2013;2(3):179-185

[4]. Ayinmode BA, Tunde-Ayinmode MF. Family violence among mothers seen at the University of Ilorin Teaching Hospital, Ilorin, Nigeria. SAJP. 2008;14(3):76-82

[5]. Owoaje ET, Olaolorun FM. Women at risk of physical intimate partner violence: A cross-sectional analysis of a low-income community in southwest Nigeria. African Journal of Reproductive Health. 2012;16(1):43-55

[6]. Bello S, Ndipon WO, Mpama EA, Oduwole OO. Pattern of alcohol use among drivers of commercial vehicles in Calabar, Nigeria. East African medical Journal. 2011;88(3):75-79

[7]. Abasiubong F, Udobang JA, Idung AU, Udoh SB, Jombo HE. A comparative study of pattern of substance use in two Nigerian cities located in the southern and northern Nigeria. African Research Review. 2014;8(2):52-67

[8]. Kalayi GD. Mortality from burns in Zaria: An experience in a developing economy. East African Medical Journal 2006;83(8):461 464.

[9]. Afolabi MO, Abioye-Kuteyi EA, Fatoye FO, Bello IS, Adewuye AO. Pattern of depression among patients in a Nigerian familypractice population. SA FamPract. 2008;50(2):63-68

[10]. James BO, Jenkins R, Lawani AO, Omoaregba JO. Depression in primary care: the knowledge, attitudes and practice of general practitioners in Benin City, Nigeria. S AfrFamPract. 2012;54(1):55-60 